\title{
Medication and medical diagnosis as risk factors for falls in older hospitalized patients
}

\author{
Fabian Wedmann ${ }^{1,2}$ (D) Wolfgang Himmel ${ }^{3}$ (D) $\cdot$ Roland Nau $^{1,2}$ (D)
}

Received: 20 November 2018 / Accepted: 27 February 2019 / Published online: 26 March 2019

(C) The Author(s) 2019

\begin{abstract}
Objective To examine the impact of medication and medical conditions on the fall risk in older hospitalized patients. Design Matched case-control study.

Setting Large regional hospital in a mid-sized German city.

Subjects Four hundred eighty-one inpatients aged $\geq 65$ years who fell during hospitalization ("cases") and a control group of 481 controls, matched for age, gender, and hospital department.

Methods Diagnosis, medication, vital parameters, and injuries were compared between cases and controls. Univariate and multivariable odds ratios (ORs) and their corresponding 95\% confidence intervals (CIs) were calculated.

Main results Several drugs were significantly associated with falls in multivariate analyses: long-acting benzodiazepines (adjusted OR $=3.49 ; 95 \%$-CI $=1.16-10.52$ ), serotonin-noradrenalin reuptake inhibitors (SNRI) $(2.57 ; 1.23-5.12)$, Z-drugs (2.29; 1.38-3.59), low-potency neuroleptics (1.87; 1.08-3.23), ACE inhibitors/sartans (1.42; 1.07-1.89). Digoxin (0.32; $0.11-0.99)$ and aldosterone receptor antagonists $(0.54 ; 0.33-0.88)$ were negatively associated with falls. No significant association in multivariate analyses was found for short- and intermediate-acting benzodiazepines, mirtazapine, and opioids. Hyponatremia $(1.52 ; 1.15-2.03)$ and leukocytosis $(1.39 ; 1.05-1.87)$ in blood examination on admission showed significant association with falls. As secondary diagnoses, Parkinson syndrome $(2.38 ; 1.27-4.46)$ and delirium (3.74; 2.26-6.21) were strongly associated with falls. The use of more than one psychoactive drug was a separate risk factor for falls $(p<0.0001)$.

Conclusion Several drugs including SNRI, neuroleptics, and Z-drugs showed a significant association with inpatient falls. The frequently prescribed tetracyclic antidepressant mirtazapine did not appear to increase the risk of falls. Psychoactive polypharmacy should be avoided.
\end{abstract}

Keywords Accidental falls $\cdot$ Psychotropic drugs $\cdot$ Mirtazapine $\cdot$ Serotonin and noradrenaline reuptake inhibitors $\cdot$ Z-drugs $\cdot$ Matched case-control study $\cdot$ Hospital $\cdot$ Aged

Key points 1 . In this case-control study, the prescription of long-acting benzodiazepines, serotonin-noradrenalin reuptake inhibitors, and lowpotency neuroleptics were associated with an increased rate of falls.

2 . The frequently prescribed tetracyclic antidepressant mirtazapine did not appear to increase the risk of falls.

3. The simultaneous use of more than one psychoactive drug should be avoided whenever possible, since it increases the risk of falls.

Roland Nau

rnau@gwdg.de

Fabian Wedmann

fwedmann@gmx.de

Wolfgang Himmel

whimmel@gwdg.de
1 Department of Geriatrics, Evangelisches Krankenhaus Göttingen-Weende, An der Lutter 24, 37075 Göttingen, Germany

2 Institute of Neuropathology, University Medical Center, Göttingen, Germany

3 Department of General Practice, University Medical Center, Göttingen, Germany 


\section{Introduction}

In hospitalized adults, especially in older patients, falls are common events which may cause fear of falling, loss of independence, injuries, and sometimes death as a consequence of injury [1]. The highest fall rates, with up to 11.7 falls per 1000 patient days, occur in geriatric departments [2]. Up to $10 \%$ of falls in geriatric wards result in serious injuries [3]. A multitude of intrinsic and extrinsic factors has been associated with falls [4]. Due to their effect on cognition and mobility, certain medication classes have been identified as risk factors for falls in older patients $[5,6]$.

Falls can be indicators of adverse drug effects [7]. Several studies reported a significantly increased risk of falls by benzodiazepines. This applies for both shortacting and long-acting compounds [5, 6]. Z-drugs are sometimes considered to be advantageous compared with benzodiazepines, particularly concerning the development of tolerance and dependence [8], but several studies have reported similar adverse effects [5].

Despite a wealth of studies on the impact of drugs on the risk of falls, there are two major gaps in our knowledge:

1. There is anecdotal evidence that some further drugs, in addition to benzodiazepines and Z-drugs, may increase the risk of falls. A large study of the safety and harms of antidepressant drugs for older people based on a large primary care database [9] found that all classes of antidepressant drugs were associated with significant increases in fall risk. To our knowledge, this has never been evaluated in a hospital setting.

2. Simple correlation analyses between drugs and falls may under- or overestimate the risk of falls, when the patients ' medical conditions are not considered. For example, when neurological symptoms which provoke falls are treated with anti-Parkinson drugs, it is not clear whether these drugs or the underlying conditions increase the risk of falls ("confounding by indication").

The aim of this study was to identify medication and medical conditions associated with falls in older inpatients of a general hospital, using a case-control design that allows for a simultaneous control of drugs and diagnoses.

\section{Method}

\section{Context}

The present study is part of a larger project in primary and secondary care to develop, implement, and evaluate strategies to reduce the use of hypnotics and sedatives $[10,11]$.

\section{Setting}

The study took place in a regional German hospital (485 beds) with departments of internal medicine, geriatrics, trauma surgery/ orthopedics, general surgery, plastic surgery, urology, and otorhinolaryngology. It was approved by the Ethics Committee of the University Medicine Göttingen and was supported by a research grant from the German Ministry of Health (II A5-2513DSM228).

\section{Patients and measurements}

Using a case-control design, we aimed to identify all patients aged 65 years or older, for whom an incident of a fall was reported between 01 January 2013 and 31 December 2013. Falls were identified by retrospective analysis of digital inpatient fall protocols filled out by the nurses of the respective departments. A control group of patients with no falls was matched by age, gender, and department in equal numbers to cases. The medication in the $24 \mathrm{~h}$ prior to the fall was analyzed. For comparison with the matched pairs of the control group, we calculated the median of the interval between admission and fall ( $=5$ days) and compared the medication in the $24 \mathrm{~h}$ prior to the fall with the medication on day 5 in the control group. Data were collected from incident reports and medical records. Injuries following falls were divided into three groups: (i) minor injuries (including superficial skin defects), (ii) moderate injuries (lacerations, hematomas), and (iii) major injuries (fractures, dislocations, cerebral hemorrhage). We calculated the Charlson Comorbidity Index on the basis of the information available. Several routine laboratory parameters (performed in all patients) and the geriatric assessments (performed in the geriatric department only) consisting of Barthel Activity of Daily Living Index, Tinetti Mobility Test, Timed-Up-and-Go Test, and Mini-Mental Status Exam were also recorded both in fall and control patients. Because of the low number of patients assessed, Barthel Index, Tinetti Mobility Test, Timed-Up-and-Go Test, and Mini-Mental Status Exam were not included in the multivariable analysis.

\section{Analysis}

Comparing cases and controls, we first analyzed the association between falls and the patients' medication and conditions and calculated crude odds ratios (ORs) and their $p$ values. Variables, i.e., drugs and conditions that matched the entry criterion of a $p$ value of 0.25 or less in univariate analyses were entered into the multivariate logistic regression model. We used this relatively high entry criterion of 0.25 , because lower $p$ values as entry criterion failed to reduce confounding in logistic regression analyses $[12,13]$.

Since diagnoses and drugs or other factors under study may be correlated, at least to a certain degree, the danger of multicollinearity arises, meaning that two or more highly 
correlated predictors make the conclusions about the relation between outcome (i.e., falls) and predictors (i.e., drugs, diagnoses) incorrect. We examined multicollinearity through the variation inflation factor, tolerance and an eigensystem analysis. A lack of multicollinearity is indicated by a value below 10 for variance inflation, a value above 0.1 for tolerance and rather large eigenvalues and small corresponding condition numbers [14].

We defined the use of more than one psychoactive drug as psychoactive polypharmacy. The Wilcoxon test was used to compare the number of psychoactive drugs taken simultaneously of cases and controls as well as the scores of our calculation of the Charlson Comorbidity Index.

All statistical analyses were performed using SAS 9.4.2 for Windows.

\section{Results}

During the study period, a total of 481 patients were identified to have a fall incidence ("cases"), resulting in an incidence rate of 4.36 per 1000 patient days. Most of the patients came from the geriatric department $(n=209)$, followed by internal medicine (171), and trauma surgery (59). The rate of women among the sample was $58.8 \%$, reflecting the higher rate of women among the older hospital population. The average age was 82 years (Table 1). The two groups did not differ significantly in their comorbidity (median Charlson Comorbidity Index of 5.0 for cases and 4.9 for control patients, $p=0.09$ ). In two-thirds of cases, the falls did not result in any injuries; minimal and moderate injuries happened in $30.7 \%$ of all falls, whereas $3.7 \%$ of all

Table 1 Sample characteristics

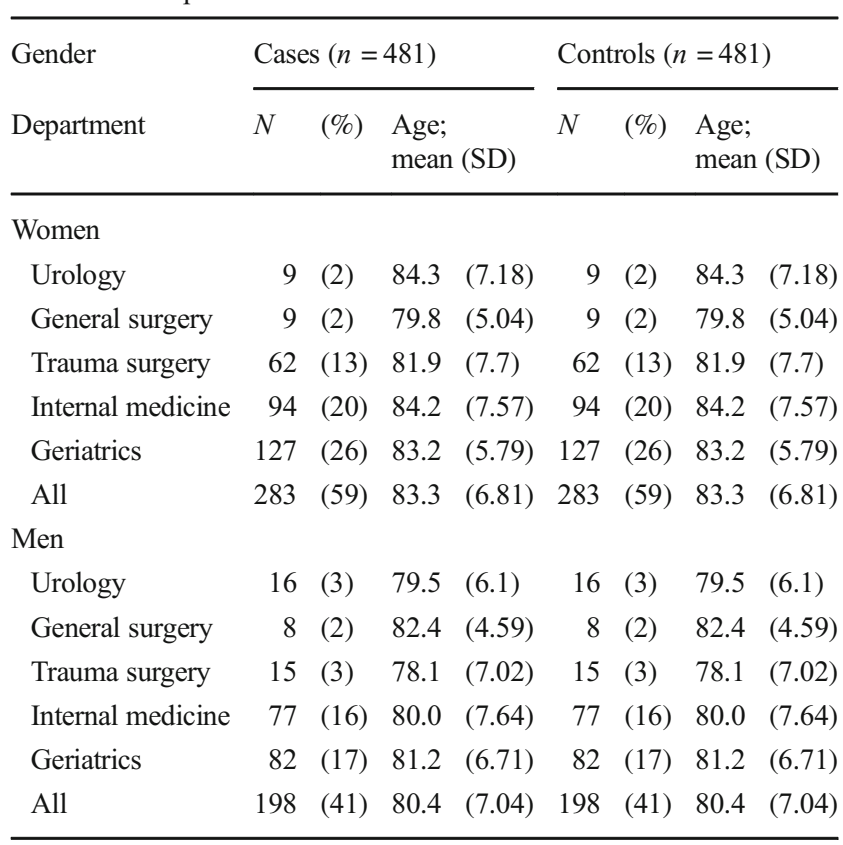

falls resulted in major injuries. One anticoagulated patient died as a consequence of subarachnoid hemorrhage.

Table 2 compares the association between falls and different risk factors for cases and controls. While the left side of the table shows the results of the univariate logistic regression with those risk factors that differed between both groups with $p<0.25$, the right side of the table shows the results of the multivariable logistic regression in which all factors from the left side were entered stepwise with an entry criterion of $p=$ 0.25 and a level for stay of $p=0.1$ so that about half of the factors on the left side remained in the multivariable model of the right side. The adjusted odds ratios were rather similar to the univariate odds ratios and their direction (below zero vs. above zero) changed in no case.

We can exclude a high inter-correlation of the factors under study and, consequently, multicollinearity. All values for variance inflation were below 1.4, i.e., far away from 10; the values for tolerance were above 0.7 , i.e., far away from 0.1 ; all eigenvalues were far away from zero and all corresponding condition numbers not large (the largest being 51.7).

Five groups of medication were significantly more often administered to cases than to control patients, i.e., showed an increased risk of falls: long-acting benzodiazepines (adjusted OR, 3.49; 95\% confidence interval, 1.16-10.52), SNRI (2.57; $1.23-5.12)$, Z-drugs $(2.29 ; 1.38-3.59)$, low antipsychotic potential neuroleptics, and angiotensin converting enzyme (ACE) inhibitors or sartans. In contrast, two medications were less frequently administered to cases, i.e., showed a reduced risk of falls: digoxin $(0.32 ; 0.11-0.99)$ and aldosterone receptor antagonists. Short-acting benzodiazepines, tetracyclic antidepressants (solely mirtazapine was prescribed in this study), and opioids showed no significant association with falls. After calculation of dose equivalents for benzodiazepines, Z-drugs, and opioids, only Z-drugs showed a dose-dependent effect on falls $(p=0.02)$.

Cases and controls differed significantly in several blood parameters on admission, such as hyponatremia and leukocytosis. Diagnoses were categorized in principal diagnoses based on ICD-10 codes and secondary diagnoses. In most cases, they were more frequent among cases than controls, with dehydration, Parkinson syndrome, and delirium particularly notable with ORs of $1.85,2.4$, or 3.7 in favor of cases. Unexpectedly, the diagnoses dementia and ischemic stroke were not associated with falls, and the association between falls and anemia was statistically significant only after univariate analysis. In our univariate model, patients with diseases of the urogenital system (ICD codes N00-N99), which include impaired renal function and diseases of the kidney, showed a tendency towards more falls, but the difference between patients with falls and control patients was not statistically significant $(p=0.09)$. Plasma creatinine in patients with falls was $1.3 \pm 0.84 \mathrm{mg} / \mathrm{dl}$ and in control patients $1.2 \pm$ 
Table 2 Factors associated with falls

Univariate model*

Factor

Short- and intermediate-acting benzodiazepines

$\begin{array}{llll}\text { No falls } & 52 & 10.8 & 1.0\end{array}$

$\begin{array}{llll}\text { Falls } & 68 & 14.1 & 1.36\end{array}$

OR $* * * \quad(95 \% \mathrm{CI})$

1.36

$(0.92-2.0)$

0.12

Long-acting benzodiazepines

$\begin{array}{lccc}\text { No falls } & 5 & 1.04 & 1.0 \\ \text { Falls } & 14 & 1.91 & 2.85\end{array}$

Low antipsychotic potential neuroleptics

$\begin{array}{llll}\text { No falls } & 26 & 5.4 & 1.0 \\ \text { Falls } & 44 & 9.2 & 1.76\end{array}$

SNRI

No falls

$14 \quad 2.9$

1.76

$(1.07-2.91)$

0.03

$(1.08-3.23)$

0.03

Falls

27

1.0

SSRI

No falls

$\begin{array}{ll}37 & 7.7\end{array}$

7.7

1.98

$(1.03-3.83)$

0.04

2.51

$(1.23-5.12)$

0.01

Falls

$50 \quad 10.4$

$$
1.0
$$

Tetracyclic antidepressants*****

$\begin{array}{llll}\text { No falls } & 61 & 12.7 & 1.0\end{array}$

Falls

$83 \quad 17.3$

$17.3 \quad 1.44$

$6.9 \quad 1.0$

No falls

$\begin{array}{ll}33 & 6.9\end{array}$

$11.4 \quad 1.75$

1.75

$(1.12-2.75)$

0.01

2.29

$(1.38-3.59)$

0.01

ACE-inhibitors/sartans

$\begin{array}{llll}\text { No falls } & 275 & 57.2 & 1.0 \\ \text { Falls } & 308 & 64.0 & 1.3\end{array}$

Aldosterone receptor antagonists

No falls $\quad 54$

Falls $\quad 33$

$11.2 \quad 1.0$

$6.9 \quad 0.58$

.33

$(1.03-1.73)$

0.03

1.42

$(1.07-1.89)$

0.03

Falls

Antihypertensive drugs not recommended by the PRISCUS-list (doxazosin, clonidine, isosorbidemononitrate, nifedipine)

0.58

$(0.37-0.92)$

0.02

0.54

$(0.33-0.88)$

0.03
No falls

$\begin{array}{ll}7 & 1.5 \\ 3 & 0.6\end{array}$
$1.5 \quad 1.0$
$0.42 \quad(0.11-1.65)$
0.2

$\begin{array}{ccc}\text { Falls } & 3 & 0.6 \\ \text { Antiarrhythmic drugs not recommended by PRISCUS-list (digoxin) }\end{array}$

$\begin{array}{lccc}\text { No falls } & 17 & 3.53 & 1.0 \\ \text { Falls } & 4 & 0.38 & 0.22\end{array}$

Opioids

No falls

$\begin{array}{llc}168 & 34.9 & 1.0 \\ 151 & 31.4 & 0.85\end{array}$

1.0
0.22

(0.08-0.68)

0.004

(0.11-0.99)

0.04

Falls

31.4

0.85

(0.65-1.12)

0.24

Diagnosis

Parkinson syndrome

\begin{tabular}{|c|c|c|c|c|c|c|c|c|}
\hline No falls & 18 & 3.7 & 1.0 & & & & & \\
\hline Falls & 36 & 7.5 & 2.08 & $(1.16-3.72)$ & 0.01 & 2.38 & $(1.27-4.46)$ & 0.02 \\
\hline \multicolumn{9}{|l|}{ Dementia } \\
\hline No falls & 77 & 16.0 & 1.0 & & & & & \\
\hline Falls & 95 & 19.8 & 1.29 & $(0.93-1.80)$ & 0.13 & & & \\
\hline \multicolumn{9}{|c|}{ Ischemic stroke } \\
\hline No falls & 77 & 16.0 & 1.0 & & & & & \\
\hline Falls & 92 & 19.1 & 1.3 & $(0.89-1.73)$ & 0.2 & & & \\
\hline
\end{tabular}


Table 2 (continued)

\begin{tabular}{|c|c|c|c|c|c|c|c|c|}
\hline \multirow[b]{2}{*}{ Factor } & \multirow[b]{2}{*}{$N$} & \multirow[b]{2}{*}{$\%$} & \multicolumn{3}{|c|}{ Univariate model* } & \multicolumn{3}{|c|}{ Multivariate model $* *$} \\
\hline & & & $\mathrm{OR} * * *$ & $(95 \% \mathrm{CI})$ & $p$ & $\mathrm{OR} * * *$ & $(95 \% \mathrm{CI})$ & $p$ \\
\hline \multicolumn{9}{|c|}{ Dehydration } \\
\hline No falls & 63 & 13.1 & 1.0 & & & & & \\
\hline Falls & 108 & 22.5 & 1.9 & $(1.37-2.7)$ & 0.0001 & 1.85 & $(1.28-2.57)$ & 0.0002 \\
\hline \multicolumn{9}{|l|}{ Delirium } \\
\hline No fall & 23 & 4.8 & 1.0 & & & & & \\
\hline Fall & 81 & 16.8 & 4.03 & $(2.49-6.53)$ & 0.0001 & 3.74 & $(2.26-6.21)$ & 0.0001 \\
\hline \multicolumn{9}{|c|}{ Blood examination } \\
\hline \multicolumn{9}{|l|}{ Anemia } \\
\hline No falls & 298 & 62.0 & 1.0 & & & & & \\
\hline Falls & 329 & 68.4 & 1.33 & $(1.02-1.73)$ & 0.04 & & & \\
\hline \multicolumn{9}{|c|}{ Hyponatremia } \\
\hline No falls & 155 & 32.2 & 1.0 & & & & & \\
\hline Falls & 200 & 41.6 & 1.49 & $(1.15-1.95)$ & 0.003 & 1.52 & $(1.15-2.03)$ & 0.003 \\
\hline \multicolumn{9}{|c|}{ Leukocytopenia } \\
\hline No falls & 10 & 2.1 & 1.0 & & & & & \\
\hline Falls & 18 & 3.7 & 1.83 & $(0.84-4.01)$ & 0.12 & & & \\
\hline \multicolumn{9}{|c|}{ Leukocytosis } \\
\hline No falls & 151 & 31.4 & 1.0 & & & & & \\
\hline Falls & 188 & 39.1 & 1.40 & $(1.08-1.83)$ & 0.01 & 1.39 & $(1.05-1.87)$ & 0.02 \\
\hline \multicolumn{9}{|c|}{$\mathrm{CRP}>5 \mathrm{mg} / \mathrm{l}$} \\
\hline No falls & 120 & 25.0 & 1.0 & & & & & \\
\hline Falls & 153 & 31.8 & 1.29 & $(0.91-1.84)$ & 0.02 & & & \\
\hline \multicolumn{9}{|c|}{ Diagnosis ICD-10 } \\
\hline \multicolumn{9}{|c|}{ C00-D48 neoplasms } \\
\hline No falls & 33 & 6.9 & 1.0 & & & & & \\
\hline Falls & 53 & 11.0 & 1.68 & $(1.07-2.65)$ & 0.02 & 1.85 & $(1.13-3.01)$ & 0.03 \\
\hline \multicolumn{9}{|c|}{ K00-K93 diseases of the digestive system } \\
\hline No falls & 56 & 11.64 & 1.0 & & & & & \\
\hline Falls & 32 & 6.64 & 0.54 & $(0.34-0.85)$ & 0.01 & 0.49 & $(0.29-0.81)$ & 0.003 \\
\hline \multicolumn{9}{|c|}{ M00-M99 diseases of musculoskeletal system and connective tissue } \\
\hline No falls & 53 & 11.0 & 1.0 & & & & & \\
\hline Falls & 38 & 7.9 & 0.69 & $(0.45-1.07)$ & 0.1 & & & \\
\hline \multicolumn{9}{|c|}{ N00-N99 diseases of genitourinary system } \\
\hline No falls & 35 & 7.28 & 1.0 & & & & & \\
\hline Falls & 50 & 10.4 & 1.48 & $(0.94-2.32)$ & 0.09 & & & \\
\hline \multicolumn{9}{|c|}{ S00-T98 injury, poisoning, and certain other consequences of external causes } \\
\hline No falls & 81 & 16.8 & 1.0 & & & & & \\
\hline Falls & 97 & 20.2 & 1.25 & $(0.90-1.73)$ & 0.18 & & & \\
\hline
\end{tabular}

*Only variables reported with $p<0.25$ in the univariate analysis (later entered into multiple logistic regression analysis)

$* *$ Variables remaining statistically significant $(p \leq 0.05)$ after stepwise logistic regression

$* * *$ Odds ratios $(95 \%$ confidence interval)

$* * * *$ Of this group, only mirtazapine was used in the present study

$0.78 \mathrm{mg} / \mathrm{dl}$ (means $\pm \mathrm{SD}, p=0.056, t$ test). The glomerular filtration rates were estimated by the Chronic Kidney Disease Epidemiology Collaboration (CKD-EPI) formula
(eGFR) in 352 patients with falls $(50.35 \pm 24.62 \mathrm{ml} / \mathrm{min})$ and in 373 control patients $(55.31 \pm 27.97 \mathrm{ml} / \mathrm{min}$; means $\pm \mathrm{SD}, p=0.012, t$ test). Diseases of the digestive tract 
(ICD-10 codes K00-K93) showed a reduced risk of falls (0.49; 0.29-0.81).

Patients with falls received a higher number of psychoactive drugs than matched control patients $(p<0.001)$. Univariate evaluation of the geriatric assessments showed no significant associations between falls and Barthel Index, Timed-Up-and-Go Test, and Mini-Mental Status Exam. The mean Tinetti Mobility Test score was lower in patients with falls than in control patients $(6.70 \pm 6.46$ versus $8.80 \pm 7.72$, $p=0.008 t$ test), and a score below 20 points was significantly associated with falls ( $p=0.05$, Fisher's exact test).

\section{Discussion}

Based on a large number of patients and a multivariable analysis, this study confirmed the role of several drugs as risk factors for falls, with long-acting benzodiazepines and Z-drugs among them. A previously in the hospital setting not reported finding was the prescription of SNRI as a further and independent risk factor of falls. Even after we controlled for conditions that are known to increase the likelihood of falls in the hospital environment, such as delirium and Parkinson syndrome, this risk factor remained significant. In contrast, there was no evidence that mirtazapine significantly contributed to falls in elderly patients.

A major strength of this study is the large sample of patients across all departments of a typical German hospital over an entire year. In a multivariable analysis, we rigorously controlled the influence of different groups of drugs and medical conditions as risk factor for falls. It is, therefore, rather unlikely that the effect of drugs on falls was strongly confounded by indication. Although the analysis is based on patients from only one hospital, it is a rather typical, rather large hospital with different departments. The gender mix of the study sample with $59 \%$ women is close to the German Hospital Statistics [15] for patients $>64$ yrs., with a rate of 54\% hospitalized women. The somewhat higher rate in our sample is due to the high rate of patients from geriatric wards, who are especially threatened by falls. At the geriatric department of our hospital, patients undergo a risk assessment on admission. To avoid inappropriate drug prescribing, all departments of the hospital use an electronic prescribing tool. Patients with an unsteady gate are encouraged not to walk without personal assistance, and prevention of falls is one main goal of physiotherapy.

A major limitation of this study is its retrospective character. Compared with follow-up studies or even randomized controlled trials, retrospective studies cannot establish a causal relationship between exposure and event. Moreover, casecontrol studies are, in principle, subject to bias, in our case the presence of confounding variables. There are different approaches to reduce confounding, such as matching of cases and controls. We matched patients by age, gender, and department, but not for diagnoses. Other studies also matched cases and controls according to diagnoses or length of hospital stay $[16,17]$. Our matching according to department, apart from age and gender, may have helped to reduce confounding, since "department" may be considered a proxy for a cluster of diagnoses and length of hospital stay and the Charlson Comorbidity Index did not differ significantly between both groups. Although diseases of the genitourinary system (ICD N00-N99) were not significantly more frequent in fall patients than in control patients, based on the eGFR, renal impairment of patients with falls was slightly more pronounced than of control patients (mean eGFR 50.35 versus 55.31). Caution is needed concerning the number and selection of matching variables since with a growing number of matching variables, the cases and controls will become increasingly similar with respect to the exposure of interest, and the study may produce a spurious result or provide no information [18].

Another possibility to reduce confounding is the use of a multivariable logistic regression model. So, we could control the possible effect of diseases and other factors and thus approximately determine the "true" effect of the medication under study. Our decision to select the median of days prior to the fall as the day of investigation for control patients could have underestimated the use of medication in the control group.

While in many studies benzodiazepines, due to their effect on cognition, postural stability, and mobility, increased the risk of falls [4-6], convincing data in inpatients are still missing for drugs recently introduced into geriatric medicine such as Zdrugs and SNRI. SNRI, commonly used in the treatment of depression, had a statistically significant association with falls in univariate and multivariable analyses. SNRIs, especially duloxetine, less frequent venlafaxine, have a broader spectrum of interactions potentially leading to adverse drug reactions including falls [19]. Hyponatremia, which was strongly associated with falls, occurs more frequently under therapy with SNRI [20]. Z-drugs had a similarly strong association with falls as SNRI, with odds ratios above 2.0 in both cases. Z-drugs are frequently used in the treatment of anxiety and insomnia but, as benzodiazepines, have an impact on cognition, balance, and coordination - as main reasons for falls [21].

Mirtazapine showed no significant association with falls in the multivariable analysis. It is a drug of choice for the treatment of geriatric depression and insomnia, thanks to its sleepinducing, antidepressant, and appetite-enhancing effects. Mirtazapine generally is well tolerated [22, 23]. In the univariate analysis, we found an association with falls, probably because mirtazapine was administered to treat depressive states or insomnia in patients suffering from Parkinson syndrome and delirium, which increased the likelihood of falls. After controlling for these variables, the association between mirtazapine and falls was no longer significant in the multivariable analysis. In our study mainly low doses of mirtazapine $(\leq 15 \mathrm{mg})$ were 
administered, and this may be one cause for the absence of a significant impact of this drug on the rate of falls. Our observation is consistent with previous results from the ambulatory setting, where mirtazapine was associated with the lowest increase of the fall risk of all antidepressants studied with an odds ratio of 1.2 [9]. Further studies should address whether doses > $15 \mathrm{mg}$ of mirtazapine are associated with a higher risk of falls than low doses in geriatric inpatients.

Compared with recent studies, we found divergent results for ACE inhibitors/sartans, digoxin, and aldosterone receptor antagonists $[5,6]$. The reasons for the unexpected increase in falls during ACE inhibitor/sartan medication may be the consequent titration of ACE inhibitors/sartans up to maximum tolerated doses at our institution in patients with cardiac failure, which often lowers blood pressure and may have caused orthostatic dysregulation. In several studies, digoxin increased mortality in patients with atrial fibrillation and flutter [24, 25]. In our hospital, digoxin and digitoxin are used with great caution with the only indication "tachyarrhythmia in patients with atrial fibrillation or flutter, when adrenergic beta-blockers are not effective enough or contraindicated." When used restrictively as in the present study, digoxin appeared not to increase the risk of falls possibly by avoiding tachyarrhythmic episodes. Congestive heart failure is an independent risk factor for falls [26]. Aldosterone receptor antagonists often improve cardiac output and thereby may reduce the frequency of falls [27]. We used spironolactone in frail and non-frail geriatric patients with strict monitoring of renal function and plasma potassium. Unlike in previous reports [28], the diagnosis of dementia did not increase the fall risk in this study probably because of the high prevalence of dementia in patients with and without falls.

Polypharmacy can cause drug-to-drug interactions and adverse drug effects $[29,30]$. Psychoactive polypharmacy, i.e., the simultaneous use of more than one psychoactive drug, was highly associated with falls in this study and should, therefore, avoided whenever possible.

In conclusion, we found a clear association between several classes of psychoactive drugs and falls in geriatric patients. In particular, the use of more than one psychoactive drug increased the risk of falls in geriatric patients. In this study, mirtazapinefrequently used in geriatric medicine because of its favorable spectrum of effects - did not increase the incidence of falls.

Acknowledgments We thank Professor Marija Djukic, Department of Geriatrics, Evangelisches Krankenhaus Göttingen-Weende, Göttingen, Professor Eva Hummers, Department of General Practice, University Medical Center, Göttingen, and Olaf Hußmann, Head of Nursing Management, Evangelisches Krankenhaus Göttingen-Weende, Göttingen, for their continuous support. Professor Rainer Muche, Department of Epidemiology and Medical Biometry, University of Ulm, helped to refine the statistical analysis.

Funding information The study was supported by a research grant from the German Ministry of Health (II A5-2513DSM228).

\section{Compliance with ethical standards}

The study was approved by the Ethics Committee of the University Medicine Göttingen.

Conflict of interest All authors have no commercial interests in drugs mentioned in this manuscript. R. Nau received honoraria for lectures by Bayer Vital, Pfizer, and Bristol-Myers Squibb. He received an honorarium by Desitin for counseling and research support by Novartis. The honoraria and research support were not related to drugs studied in this manuscript.

Open Access This article is distributed under the terms of the Creative Commons Attribution 4.0 International License (http:// creativecommons.org/licenses/by/4.0/), which permits unrestricted use, distribution, and reproduction in any medium, provided you give appropriate credit to the original author(s) and the source, provide a link to the Creative Commons license, and indicate if changes were made.

\section{References}

1. Cameron ID, Gillespie LD, Robertson MC, Murray GR, Hill KD, Cumming RG, Kerse N (2012) Interventions for preventing falls in older people in care facilities and hospitals. Cochrane Database Syst Rev 12:CD005465

2. Bouldin ED, Andresen EM, Dunton NE, Simon M, Waters TM, Liu M, Daniels MJ, Mion LC, Shorr RI (2013) Falls among adult patients hospitalized in the United States: prevalence and trends. J Patient Saf 9:13-17

3. Berry SD, Miller RR (2008) Falls. Epidemiology, pathophysiology, and relationship to fracture. Curr Osteoporos Rep 6:149-154

4. Bueno-Cavanillas A, Padilla-Ruiz F, Jiménez-Moleón JJ, PeinadoAlonso CA, Gálvez-Vargas R (2000) Risk factors in falls among the elderly according to extrinsic and intrinsic precipitating causes. Eur J Epidemiol 16:849-859

5. Woolcott JC, Richardson KJ, Wiens MO, Patel B, Marin J, Khan KM, Marra CA (2009) Meta-analysis of the impact of 9 medication classes on falls in elderly persons. Arch Intern Med 169:1952-1960

6. Park H, Satoh H, Miki A, Urushihara H, Sawada Y (2015) Medications associated with falls in older people: systematic review of publications from a recent 5 -year period. Eur $\mathrm{J}$ Clin Pharamcol 71:1429-1440

7. Lavan AH, Gallagher P (2016) Predicting risk of adverse drug reactions in older adults. Ther Adv Drug Saf 7:11-22

8. Conn DK, Madan R (2006) Use of sleep-promoting medications in nursing home residents: risks versus benefits. Drugs Aging 23:271-287

9. Coupland C, Dhiman P, Morriss R, Arthur A, Barton G, HippisleyCox J (2011) Antidepressant use and risk of adverse outcomes in older people: population based cohort study. BMJ 2011 343:d4551

10. Arnold I, Straube K, Himmel W, Heinemann S, Weiss V, Heyden L, Hummers-Pradier E, Nau R (2017) High prevalence of prescription of psychotropic drugs for older patients in a general hospital. BMC Pharmacol Toxicol 18:76

11. Heinemann S, Weiß V, Straube K, Nau R, Grimmsmann T, Himmel W, Hummers-Pradier (2016) Understanding and reducing the prescription of hypnotics and sedatives at the interface of hospital care and general practice: a protocol for a mixed-methods study. BMJ Open 6:e011908

12. Hosmer DW, Lemeshow S, Sturdivant RX (2013) Applied logistic regression, 3rd edn. Wiley, Hoboken, New Jersey 
13. Bursac Z, Gauss CH, Williams DK, Hosmer DW (2008) Purposeful selection of variables in logistic regression. Source Code Biol Med $3: 17$

14. Schreiber-Gregory DN (2017) Multicollinearity: what is it, why should we care, and how can it be controlled? SAS Paper 14042017. Available at: http://support.sas.com/resources/papers/ proceedings17/1404-2017.pdf. Accessed 10 Nov 2018

15. Federal Bureau of Statistics (2015) Statistics of diagnoses of patients in hospitals (Series 12; 6.2.1). Statistisches Bundesamt, Wiesbaden, Germany

16. Krauss MJ, Evanoff B, Hitcho E, Ngugi KE, Dunagan WC, Fischer I, Stanley B, Shirley J, Eileen C, Victoria JF (2005) A case-control study of patient, medication, and care-related risk factors for inpatient falls. J Gen Intern Med 20:116-122

17. Chang CM, Chen MJ, Tsai CY, Ho LH, Hsieh HL, Chau YL, Liu CY (2011) Medical conditions and medications as risk factors of falls in the inpatient older people. A case-control study. Int J Geriatr Psychiatry 26:602-607

18. Rose S, van der Laan MJ (2007) Why match? Investigating matched case-control study designs with causal effect estimation. Int J Biostat 5:1

19. Knadler MP, Lobo E, Chappell J, Bergstrom R (2011) Duloxetine: clinical pharmacokinetics and drug interactions. Clin Pharmacokinet 5:281-294

20. De Picker L, Van Den Eede F, Dumont G, Moorkens G, Sabbe BG (2014) Antidepressants and the risk of hyponatremia: a class-byclass review of literature. Psychosomatics 55:536-547

21. Gunja N (2013) The clinical and forensic toxicology of Z-drugs. J Med Toxicol 9:155-162

22. Alam A, Voronovich Z, Carley JA (2013) A review of therapeutic uses of mirtazapine in psychiatric and medical conditions. Prim
Care Companion CNS Disord 15:(5). https://doi.org/10.4088/ PCC.13r01525

23. Riemann D, Baglioni C, Bassetti C, Bjorvatn B, Dolenc Groselj L, Ellis JG, Espie CA, Garcia-Borreguero D, Gjerstad M, Gonçalves M, Hertenstein E, Jansson-Fröjmark M, Jennum PJ, Leger D, Nissen C, Parrino L, Paunio T, Pevernagie D, Verbraecken J, Weeß HG, Wichniak A, Zavalko I, Arnardottir ES, Deleanu OC, Strazisar B, Zoetmulder M, Spiegelhalder K (2017) European guideline for the diagnosis and treatment of insomnia. J Sleep Res 26:675-700

24. Barry PJ, Gallagher P, Ryan C, O'Mahony D (2007) START (screening tool to alert doctors to the right treatment) - an evidence-based screening tool to detect prescribing omissions in elderly patients. Age Ageing 36:632-638

25. Charnigo R, Khairy P, Guo J, Shohoudi A, Elayi CS (2018) Use of digoxin in atrial fibrillation: one step further in the mortality controversy from the AFFIRM study. Pacing Clin Electrophysiol 16: 713-719. https://doi.org/10.1111/pace. 13350

26. Lee K, Pressler SJ, Titler M (2016) Falls in patients with heart failure: a systematic review. J Cardiovasc Nurs 31:555-561

27. Japp D, Shah A, Fisken S, Denvir M, Shenkin S, Japp A (2017) Mineralocorticoid receptor antagonists in elderly patients with heart failure: a systematic review and meta-analysis. Age Ageing 46:18-25

28. Hill KD, Vu M, Walsh W (2007) Falls in the acute hospital settingimpact on resource utilisation. Aust Health Rev 31:471-477

29. Mallet L, Spinewine A, Huang A (2007) The challenge of managing drug interactions in elderly people. Lancet 370:185-191

30. Hammond T, Wilson A (2013) Polypharmacy and falls in the elderly: a literature review. Nurs Midwifery Stud 2:171-175

Publisher's note Springer Nature remains neutral with regard to jurisdictional claims in published maps and institutional affiliations. 